\title{
Inside the black box: incentive regulation and incentive channeling on energy markets
}

\author{
Klaus Heine
}

(C) The Author(s) 2011. This article is published with open access at Springerlink.com

\begin{abstract}
This paper aims to achieve more insight into the complex interplay between the "external" market regulations and "internal" regulations (corporate governance) of energy firms. In recent years, many countries have deregulated the incumbent energy monopolies and have introduced new modes of regulation. However, the new incentive schemes do not represent an unmitigated success story. A major problem seems to be the neoclassical framework that is used for the analysis of energy markets. Therefore, an important goal of this paper is to clarify the boundaries of neoclassical regulation theory. There are two restrictions that hamper the neoclassical analysis of energy markets. The first is the difficulty of overcoming the widely held "black box" view of firms. The second is the idea that agents always make rational choices. The paper proposes a kind of theoretical division of labor for understanding the effectiveness of regulatory schemes in energy markets. Neoclassical economics points out to the sources of market failure, and helps to identify where in particular on the supply chain one is likely to observe natural monopolies. Transaction cost economics explains appropriate governance of vertical relations along the supply chain. And organizational theories can elucidate what happens within firms: their response to regulation, competition, and relations with suppliers. A research agenda for the third component is proposed, drawing on insights from New Sociological Institutionalism and organizational behavior.
\end{abstract}

\footnotetext{
K. Heine $(\bowtie)$

Law School, Rotterdam Institute of Law and Economics, Erasmus University Rotterdam, Burgemeester Oudlaan 50, Postbus 1738, 3000 DR Rotterdam, The Netherlands e-mail: heine@frg.eur.nl
} 
Keywords Energy markets - Public utilities - Incentive regulation - Incentive channeling - Transaction cost economics - New sociological institutionalism . Organizational behavior

\section{Outline}

In recent years, the regulation of the electricity and gas markets (henceforth "energy markets") has undergone substantial changes. Electricity markets in particular have become more and more deregulated in most countries and have become the forerunner in applying new modes of regulation (DG Competition 2007; Spence 2008). However, the deregulation of energy markets is not an unmitigated success story. There is often the complaint that energy prices remain high, the investments into the energy infrastructure (especially power plants and the power grid) are seen to be too low, or the security of energy supply is lowering and the implementation of green technologies is rather slow. To be true, yet it is not clear whether the state of affairs would be better without deregulation. Also, the specific regulatory results may vary from case to case and from country to country (see e.g. KEMA-report 2005; or Eurostat Electricity prices for EU households and industrial consumers). For these reasons it is beyond this article to decide whether the newer regulation schemes of the energy sector are based on an improper theory of (de-)regulation. In the opposite, one can expect a learning process of regulators and regulated firms, in which the regulation schemes are improved and regulatory outcomes become over time more satisfying (for an example see Majumdar 1997).

The approach taken in this article is proposing that the incentive-based regulation of energy markets could be improved, if insights from organizational science would be considered more systematically for the design of the newer regulation schemes. However, integrating insights of organizational science with the mainstream approach of regulating energy markets is challenging and has to consider a multitude of different aspects. For that reason this article has to be seen as a sort of "door opener" for further research and not as a "capstone" of an established research agenda. Although this means that yet not all problems of that research agenda have been fixed, it should become clear that there is added value of this line of research, and that it is possible to derive some important policy conclusions from this agenda.

In the following, first the neoclassical approach to regulating energy markets will be briefly explained. Afterwards it will be discussed, why in neoclassical economics the firm remains a "black box" and why corporate governance and organizational issues are essential for a proper regulation of energy firms. The remaining portions of the paper then consider in more detail organizational issues. Thereby insights from New Sociological Institutionalism become integrated with mainstream economic reasoning, in order to get a broader picture of the governance problems which are involved in recent endeavors for better regulation of energy markets. Especially the channeling of regulatory incentives through the corporate governance to the decision making agents will be considered as well as in which way incentive channeling may be improved. 


\section{The boundaries of neoclassical analysis}

\subsection{Setup of the problem}

In ordinary markets, competition is an automatic incentive device that makes sure that, in the long run, only those sellers will prevail that can offer products at a competitive price and that adopt efficient corporate governance structures. Those firms which cannot manage for a properly working corporate governance structure are subject to severe problems and may have to file for bankruptcy (Kole and Lehn 1997, 1999; Alchian 1950).

However, energy markets are different. While in ordinary markets production functions have decreasing returns to scale, firms in energy markets operate with a production function of increasing returns to scale, which leads to a market structure of natural monopoly. The crucial point is that natural monopoly constitutes a sort of market failure (Viscusi et al. 2005), and market selection is interrupted. That is, in the case of a natural monopoly, there is no automatic mechanism that channels price signals from competitive markets via the corporate governance structure through the decision-making agent. Also, corporate governance structures will not adapt automatically to efficiency-enhancing modes. On the contrary, profits from monopoly power allow energy firms to conserve inappropriate governance structures (Kole and Lehn 1997).

From a normative point of view, the structurally hampered market process affords a sort of regulatory intervention that constrains the uncontrolled exercise of monopoly power. Therefore, in the past, the energy sector has been heavily regulated by jurisdictions. In many countries, energy firms became directly (e.g., France) or indirectly (e.g., Germany, Switzerland) state-owned-or, at least, the government executed broad regulatory oversight over private energy firms (e.g., the United States of America and the United Kingdom). The traditional regulation schemes were intended to overcome the problem of natural monopoly and to implement second-best solutions. However, over the years, it became clear that the traditional method of regulating energy markets did not function well. Energy prices remained high in comparison to the prices indicated for other markets (Goerten and Clement 2006; Eurostat 2006), the investment in new technologies was low or arbitrary, and customer service was bureaucratic (Mikkelsen et al. 2002). Therefore, since the 1980s, a growing number of jurisdictions have tried to overcome these undesirable results by implementing new kinds of regulation. All these new regulatory policies have in common the fact that they aim to establish external incentives for energy firms to become more efficient (incentive regulation) and question the level of vertical integration of energy firms.

\subsection{The refinements of market failure: of politicians and agents}

In recent years, there have been two theoretical developments in regulation theory that have aimed to improve the regulation of network industries in general and energy firms in particular. 
The first development belongs to the Public Choice school (for an overview see Mueller 2004). This school of thought claims that the strong influence of politics is responsible for the inferior regulation of energy markets. The idea is that politicians and bureaucrats are striving for office in order to maximize their individual benefits. Politicians attempt to ensure their (re-)election to office through the presentation of offers to voters (Downs 1957; Mueller 2004). For example, employees of energy firms may be promised that they will be protected against energy imports from other jurisdictions (Maloney et al. 1984), or the promise may be made that wages will be marked up, that takeovers in the energy sector will be legally blocked or that certain technologies will be discarded (like coal or nuclear power). All these political initiatives raise the cost of energy. Like politicians, bureaucrats are also cost-drivers of the energy sector because they seek more and more competencies (Niskanen 1971; Mueller 2004), in order to legitimate growing offices and retain influence. That is, bureaucrats will invent more and more rules that have to be obeyed in energy markets. In the end, the overregulation of energy markets and the distribution of extra benefits generate an excess burden with regard to the costs of regulation.

The important point is that Public Choice no longer assumes a benevolent government as in neoclassical policy analysis. Quite the opposite is true: the government is viewed as maximizing the utility of politicians, bureaucrats and interest groups while putting the burden of regulation on the shoulders of citizens who cannot escape regulation (Olson 1965; Mueller 2004). On this basis, Public Choice concludes that energy markets have to be deregulated in order to prevent growing political interference and a growing burden of undue costs and welfare losses (Rossi 2008; Farber and Frickey 1991).

From the perspective of organization science, public choice has opened the "black box" of processes in the realm of politics, but Public Choice remains silent with regard to the processes that are undertaken inside regulated firms. Therefore, Public Choice represents a strong critique of neoclassical welfare economics but assumes firms to be still represented by production functions.

The second development is not in opposition to neoclassical economics; it is rather a series of specifications of neoclassical arguments. The first specification is concerned with the vertical integration of energy firms. The question is which stage of energy supply exactly constitutes natural monopoly. The idea is that the only link in the supply chain that has to be regulated is the one characterized by a production function with increasing returns (Knieps 2006; Brunekreeft 2002). For one to detect this link, the supply chain has to be disaggregated. The supply chain of energy consists of the stages of energy production, energy distribution and selling of energy. While the stages of energy production and selling of energy are characterized by a production function of decreasing returns, the distribution of energy through the power grid is characterized by increasing returns (e.g. Knieps 2006), because the more energy-consuming units are connected to the grid, the more the interconnection costs per unit will decrease.

The identification of the power grid as the regulatory bottleneck has apparent consequences for the corporate governance of energy firms. Because only the distribution of energy has the characteristics of a natural monopoly, it is the only 
part of the supply chain that has to be regulated. The other parts of the supply chain can be left to free competition. The policy implication is straightforward because it means that energy firms have to be vertically separated into autonomous units (unbundling) whereby the regulatory bottleneck (distribution of energy) has to grant free access to all producers and sellers of energy (for a discussion see Lyon and Hackett 1993).

The second specification of neoclassical economics is concerned with the informational asymmetries between the regulator and the (energy) firm which controls the net-infrastructure. In accordance with principal agent theory, it is assumed that the grid firm (agent) has superior information about the real costs of energy distribution, while the regulator (principal) has only limited information (Blackmon 1994; Laffont 1994; Kahn 2002). With the help of principal agent theory it is possible to design regulations that are intended to set incentives for the grid firm to reveal true costs (Blackmon 1994). This has become the basic idea of incentive regulation.

In summary, the neoclassical analysis contributes to the question of when and how energy markets should be regulated. But, blind spots remain. One is to view the firm as a production function, which reduces the firm from an organizational science perspective to a "black box" (Simon 1991; Williamson 1985). Alternatively, neoclassical theory breaks up the firm into single relations between principals and agents, but this is ignoring the idea that the various parts of an organization may be held together not only by bilateral contracts but also by the glue of corporate culture, identity or other processes of institutionalization (Tolbert and Zucker 1996; Scott 2001).

\subsection{Lacunae of incentive regulation}

Incentive regulation aims to mimic market incentives. The idea is that managers of grid firms should be stimulated to use their superior knowledge about cost reductions for making the distribution of energy more efficient (for an overview see Vogelsang 2002; Laffont 1994). In order to achieve this aim, incentive regulation makes a paradigmatic shift: Instead of regulating the costs of the net-infrastructure directly (so-called cost-plus regulation), it specifies a "price cap" (Acton and Vogelsang 1989; Littlechild 1983; Shleifer 1985). A "price cap" is the highest possible price that the owner of the power grid can charge in exchange for granting access to the grid for energy producers. If the owner of the power grid can manage to reduce costs below the ceiling of the "price cap", he can keep the difference as an extra profit. It is obvious that the managers of the grid firm have a strong incentive to reduce costs in order to gain that extra profit. However, it is also true that grid customers do not automatically gain an advantage from this sort of regulation because they have to pay the "price cap" anyway. Also, consumers of energy achieve no direct advantage. Therefore, the regulation authority must from time to time revise the "price cap" downwards. The possible steps downwards are determined by the presumed average cost reductions of the energy industry per regulation period, which usually lasts between 3 and 5 years (Vogelsang 2002; Braeutigam and Panzar 1993). 
There are two ways for separating the power grid from the production and sale of energy: (1) the governance mode of "legal unbundling" and (2) the governance mode of "ownership unbundling". In the case of legal unbundling, the power grid is the property of an energy firm that is also engaged in the production and sale of energy. However, under a legal unbundling regime, the power grid firm has to be an independent legal entity (for example, a public limited company or private limited company). It has the obligation to grant non-discriminatory access to the grid for all competitors in energy markets and to serve as a "common carrier". In the case of ownership unbundling, the grid firm becomes totally separated from the production and sale of energy. The owners of the grid firm must not be engaged in the production and sale of energy. Because the only operation of the grid firm is the distribution of energy, it can be expected that the grid firm will grant equal access to the grid for all producers of energy in order to maximize profits from the brokerage of grid capacities.

Thus, the effectiveness of regulation does not solely depend on the employed incentive scheme but also depends on access to the power grid and the vertical organization of the energy supply as well. This makes it intuitively clear that questions of corporate governance become highly relevant, as one has to ask in which way incentive regulation interacts with the various parts of the supply chain. Until now, however, the interaction of incentive schemes with the corporate governance of energy firms has not received much attention (Joskow 1991, 2006).

The obvious question is whether the effectiveness of incentive regulation depends on the legal form of unbundling. As yet, models of incentive regulation are silent on this point because their focus is exclusively on the impact of external regulations, whereby it is implicitly assumed that there are no countervailing effects from corporate governance. It is largely ignored that corporate governance represents a set of "internal regulations" of the firm to decision-makers. Additionally, models of incentive regulation assume that all agents behave rationally. However, this assumption may be too narrow for the analysis, given that managers are bound to "external" as well as to "internal" regulations, which both may produce contradictory incentives. It is questionable whether the resolution of those incentive conflicts can be fully explained by rational choice models, because it is often highly unclear for the decision-maker toward what end his decision will lead (Zey 1998): On the one hand, obeying strictly "external" regulation may undermine a manager's position within a firm hierarchy and may deteriorate his prospective career. On the other hand, circumventing "external" regulation may imply the risk of being punished or fined by the regulator. That is there may be a severe (intra) role conflict with the decision making agent. On the one hand the agent may feel the obligation to act in the interest of his firm and to maximize profits, although if doing so is against "external regulations". On the other hand the agent may feel the obligation to act in the interest of society he also belongs to and to obey "external regulations" (Armstrong 1978). So, managers will often have to rely on heuristics in order to cope with the uncertainty that stems from the parallelism of "internal" and "external" regulation (Tversky and Kahneman 1974; Kahneman et al. 1982; Festinger 1957). These heuristics may be biased, may be false, or may at least mirror satisficing instead of maximizing behavior. In any 
case, it is worth broadening the analysis by taking into account insights of organizational behavior, in order to gain a better understanding of incentive regulation.

\section{Broadening the analytical framework}

\subsection{The need of institutional analysis}

A result of the previous section is that a broadening of the analysis of energy regulation is promising in two respects: First, taking into account the coincidence of "external" and "internal" regulation, and second, applying a richer model of man. This broadening of the analysis is in line with the approach of modern institutional analysis (Nee 2005; Campbell and Lindberg 1990), which can be roughly differentiated into two schools. The first is New Institutional Economics, and the second is New Sociological Institutionalism. Both approaches contribute to a better understanding of organizational processes and hence to a better understanding of channeling incentives through the corporate governance to the decision making agent. However, there are important differences between the two approaches.

New Institutional Economics is a means of analyzing the self-interested but bounded rational behavior of agents in governance structures on a micro level (Williamson 1998; Furubotn and Richter 2005). This sort of analysis is goaloriented and can be used for institutional design, either on the level of "external" regulations (economic policy or law) or on the level of "internal" regulations (corporate governance, contracts or firm strategy).

New Institutional Economics is not in general conflict with orthodox microeconomics (North 1994; Posner 1993). It is rather an extension of microeconomic analysis that takes into account the bounded rationality and opportunism of agents (Richter 2005). New Institutional Economics asks in which way institutions influence or constrain the selfish behavior of agents. Thereby, it is recognized that agents are always embedded in more or less complex governance structures. The firm is no longer a black box but is instead seen as a "nexus of contracts" (Jensen and Meckling 1976). This allows for a refined analysis of incentives, which reveals the many trade-offs at play when one aims to explain real-world behavior of agents or to design institutions. With the help of New Institutional Economics, it is possible to systematically analyze the complex governance structure of "internal" and "external" regulations. Thereby, the analysis of incentives is microanalytic, and the focus is on the behavior of single agents (methodological individualism).

New Sociological Institutionalism is more composite and less microanalytic than New Institutional Economics. Powell and DiMaggio (1991, p. 8) state that New Sociological Institutionalism “... comprises a rejection of rational choice models, an interest in institutions as independent variables, a turn toward cognitive and cultural explanations, and an interest in properties of supra-individual units of analysis ...." History plays a crucial role for the understanding of institutions, too, whereby habitualization is an important trigger for institutionalization. For example, 
Berger and Luckman (1966, p. 54) explain: "Institutions ... imply historicity and control. Reciprocal typifications of actions are built up in the course of a shared history. They cannot be created instantaneously. Institutions always have a history of which they are the products." This means that the institutionalization of markets in general and of energy markets in particular may not adjust automatically towards economic efficiency but may be the result of unique events and conditions in time and space. It also spotlights the importance of political processes for the shaping of institutions (Richter 2005; Granovetter 1985, 2005).

\subsection{The corporate actor framework as a means of theory integration}

It seems reasonable to argue for an analysis of energy markets, which integrates insights from New Institutional Economics and New Sociological Institutionalism. The aim of this sort of analysis is to gain deeper insight into the complex interactions between incentive regulation and corporate governance. The necessity of this task is clearly highlighted by Verma et al. (1999, p. 408): "Although the theory [i.e., incentive regulation] predicts effects because of managers' selfinterested objectives, the incentive programs built into the newer regulation produce incentives for the firm, not necessarily for individual managers." This quote points to several analytical shortcomings of the new incentive based regulation schemes: While incentive regulation is a big step forward to mimic market incentives for the regulated firm, it neglects the fact that decision makers are always embedded into an organizational environment. This neglect of organizational issues has been traced back to an inconsistent application of methodological individualism in neoclassical economics. While in general the neoclassical framework is based on methodological individualism, governments and firms are seen as goal-oriented entities with an objective utility function, which is either the maximization of welfare or profit (Vanberg 1992; Moe 1984). That is, organizations are treated as individuals with a consistent utility function, which is obviously a methodological inconsistency, because organizations consist at least of two individuals, which entails the problem of aggregating the preferences of individuals.

However, one may think of "complex objective functions" of the management of grid firms. This is an indirect way for including organizational behavior as a decisive factor into energy regulation. While usually it is assumed that a firm behaves like a single profit maximizing agent, this approach assumes that the management may aim at other goals than profit maximization (Baumol 1959; Marris 1963; Williamson 1963). Management may be more interested in the maximization of sales, firm growth or spending money for lavish offices, extra secretarial services, luxury cars etc. The important point is that management becomes identified as a distinct organizational layer of the firm. Then the firm consists of at least two organizationally distinct groups: The firm owners and the management. This separation makes it possible to construct complex objective functions of firm behavior, which go beyond simple profit-maximization. For example, one may put sales, growth rate, profit and managerial amenities as weighted variables in an objective function of management, with which then firm behavior may be predicted. Also psychological factors may become arguments of that objective function; for 
example management may use certain routines and heuristics to achieve its goals instead of maximizing utility in each single case.

External regulation can be easily aimed at specific arguments in the objective function. But despite its seemingly great intuition one can question whether the approach of complex objective functions really solves the problem of aligning organizational issues with incentive regulation. The rationale for this is that the approach of complex objective functions, similarly to the black box view of the firm, assumes a single decision maker. Now the single decision making agent is the management to whom a complex objective function is ascribed (Leibenstein 1979).

The essence of the organizational problem is not touched by the approach of complex objective functions. If there is only one manager who is maximizing his complex utility function, than no problem exists. But what meaning can be given to a situation, if a group of managers makes a decision? Different managers may have different aims and may weigh the arguments of the complex objective function differently. How become the different utility functions of the managers aggregated? It can be assumed that the larger the management group is and the greater the number of arguments in the complex objective function are that the greater the problem (Jensen 2001). That is, only the assertion about the behavior of the black box has changed, not the analytical perspective to treat firms as black boxes (Leibenstein 1979).

The approach of complex objective functions is silent on the meaning of group size and differences in power of group members, because the approach is lacking an understanding of hierarchical conflict resolution mechanisms. Thereby it can be assumed that not only formal power relations shape group decisions, but also informal relations between group members influence group decisions (Leibenstein 1979; French and Raven 1959). In the end it is dubious whether a complex objective function can accurately mirror group decisions and the organizational behavior of firms. As a consequence it is also doubtful that regulations which are aimed at arguments of a complex objective function are smart enough to adequately change organizational behavior. What is lacking is a better understanding of the internal operations of a firm, which subsequently can be linked to a firm's legal framework.

In order to circumvent the problem of complex objective functions and to ground the analysis in methodological individualism, it is possible to interpret firms as a nexus of bilateral contracts between equal individuals (Alchian and Demsetz 1972; Jensen and Meckling 1976). An important consequence of this view is that the market-paradigm becomes extended to organizational issues and that the idea of organization boils down to a mere "legal fiction" (Jensen and Meckling 1976). Another important consequence of this approach is that the intra-firm relation between the employee and the centralized contractual agent (employer) is seen as a relation of equal powers; that is, an employee can leave as easily the firm as a buyer can switch to another grocer (Alchian and Demsetz 1972). Surely, it is possible to think of more complex settings, but what is important is that in the nexus of contracts approach key characteristics of organizations are ignored, like the features of power or loyalty (Simon 1991). However, these are important characteristics of organizations which have a large impact on the behavior of decision makers. 
In order to overcome the "black box" view of the firm on the one hand and to avoid the negation of the idea of organization by extending the market-paradigm onto intra-organizational relations, it is possible to conceive of the firm as a corporate actor (Coleman 1974; Vanberg 1992). In its external relationships, a corporate actor appears as a legal person with a uniform decision-making process and the ability to take part in business transactions. In its internal relationships, a corporate actor consists of a net of contracts between single actors or groups of actors. The corporate contract (corporate law) is the pivotal element of the internal decision-making process, which equilibrates the sometimes divergent interests of stakeholders and serves as a sort of constitution of the firm (Vanberg 1992). However, because corporate law cannot foresee all possible conflicts, the corporate contract remains incomplete (Easterbrook and Fischel 1991; Hansmann 2006), which allows actors to pursue their own aims to a certain degree and to deviate from rational maximizing behavior.

The methodological underpinning of the idea to conceive of firms as corporate actors is methodological individualism-decisions and actions can only be made by human individuals (Vanberg 1992; Coleman 1974). However, individual decision making and individual behavior within a firm is always interrelated and has to be coordinated. That is, the social mechanisms which underlie intra-organizational coordination are an important part of the analysis, if one is out to understand firm behavior.

The corporate governance of firms can be understood as the formal constitution of a corporate actor, which mirrors the social mechanisms of individuals who are trying to coordinate their individual decisions and actions. Thereby the coordinated actions of individuals may aim at profit-maximization, as neoclassical economics suggests. But, a corporate actor may also pursue other goals as long as he can manage for financial stability and legitimacy (Vanberg 1992; see also Alchian 1950).

What is important is that viewing firms as corporate actors makes it possible to base the analysis of organizations on methodological individualism and coincidentally to make a difference between organizational and individual behavior. In addition, the idea to conceive a firm's corporate governance as a constitutional contract allows integrating external regulations in a systematic way into the analysis of regulated firms. That is, external regulations may be understood as a sort of public constraint of the decision-making processes within a regulated firm. These constraints become effective by prescribing a certain market performance (e.g. a price cap), a certain market behavior (e.g. no discrimination of competitors, if they are using the net-infrastructure) or a certain market structure (e.g. legal or ownership unbundling of the grid firm).

In any case a decision maker of a regulated firm has to take into consideration both, the constitutional constraints of internal regulations (corporate governance) as well as external regulations. Thereby he has some degrees of freedom, because the private constitutional contract (corporate governance) and the public constitutional contract (regulation) remain incomplete and leave room for decisions, which may be in the interest of the decision maker but not necessarily in the interest of a firm's shareholders or the public. However, the incompleteness of internal and external 
regulations is not the only problem, there is also the problem that internal and external regulations may set contradictory constraints and incentives for the decision making agent. So, the question arises, in which way the decision making process will be affected, if there is left some room for individual decisions, which are neither constrained by internal nor external regulations, or if there are internal and external regulations which set contradictory constraints and incentives for the decision making agent.

In the following the idea of the firm as a corporate actor will be employed to integrate insights from New Sociological Institutionalism on the macro-level of firm behavior and insights from organizational behavior on the micro-level, in order to get a better understanding of the interaction of incentive regulation and corporate governance. Thereby the problem of incentive channeling will be center stage.

\section{Incentive channeling through corporate governance structures}

\subsection{Bridging the gap between regulation and corporate governance}

A starting-point for structuring the problem of incentive channeling is transaction cost economics. Transaction cost economics belongs to New Institutional Economics, but qualifies as a bridge to insights of the behavioral theory of the firm as well as to New Sociological Institutionalism (Nee 2005).

Transaction cost economics analyzes different modes of coordination that range between markets and hierarchies, thereby appreciating bounded rationality of agents and culture as important underlying for theory building (for an overview, see Williamson 1998). The notion of bounded rationality has led to sometimes fierce debates, whether transaction cost economics is alienable with neoclassical thinking (Furubotn and Richter 2005) and whether bounded rationality is a valuable concept at all (Posner 1993). Here it is not possible to discuss all arguments of that debate, however one can conclude that transaction cost economics has triggered a sort of "sociological turn" in economics, motivated by difficulties in explaining institutions within the framework of neoclassical economic theory (Nee 2005; Furubotn and Richter 2005).

In the epicenter of transaction cost economics is the "transaction", which may be broadly understood as every kind of exchange between two or more agents. Transactions are a part of all kinds of contracts or binding arrangements, including purchase contracts, employment contracts, corporate law or regulations. Those contracts belong in turn to the entire institutional environment, which might be comprised of the judicial system, the political system or the set of informal rules mediated by culture (for an overview see Nee 2005). In addition, transactions depend on the technological specifics of goods and services-for example, whether a transaction demands sunk investments or not (Williamson 1998). In any event, transactions produce costs, and the question is which governance mode minimizes those costs. That is, whenever a transaction via the market mechanism fails, than hierarchical coordination may be in order because hierarchical coordination may save transaction costs (Williamson 1998). 
In the case of energy firms, one has to determine the governance mode that minimizes the transaction costs of coordinating the energy supply chain. A hierarchical coordination of activities is given, if there is a bundling of the production, distribution and sale of energy in a legal entity, which serves as a parent company (e.g. a management holding) making all strategic decisions along the value chain. It can be argued that this governance mode is the most transaction cost-saving for energy firms because there are significant sunk costs associated with the power grid and substantial expenditures related to its technical operation, as well as the coordination between the production of energy and its transmission via the grid (Joskow 2006). More generally, the exploitation of synergies and complementarities between the production, distribution and sale of energy calls for integrated hierarchical coordination (Stieglitz and Heine 2007).

But, putting the energy supply chain under the control of integrated management raises a dilemma: On the one hand, integrated management may reduce transaction costs, bring forward synergies and enhance productivity; on the other hand, the power grid is a natural monopoly that may be abused to leverage monopoly power from the distribution of energy toward the production and sale of energy. For example, an integrated energy firm may impede access to the grid for competitors by giving priority to its own operations and run short the capacity of the grid. In effect, reducing the capacity of the grid retains monopoly profits and causes welfare losses.

At first glance, the described trade-off seems trivial, but it is of the utmost importance because it underpins the hypothesis that corporate governance is essential for attaining efficiency of energy supply. However, such efficiency depends not only on corporate governance but also on regulation. That is, only the simultaneous fine-tuning of corporate governance and regulation will enable an efficient energy supply.

There is no clear empirical evidence, whether the distortive effects on competition or the gains from synergies of an integrated supply chain of energy are larger. However, empirical studies indicate that the welfare gains from increased competition in case of ownership unbundling probably outweigh potential disruptions of synergies (Pollitt 2008). Thereby Steiner (2001) highlights the point that unbundling is superior to integration, when there is an advanced competition policy in place, which backups the (de-)regulation of the energy sector. Insofar ownership unbundling alone may not lead to welfare gains but have to be seen as a part of a whole package for restructuring energy markets.

The picture becomes complete, if one considers that there may exist a continuum of combinations of corporate governance modes and regulations. For example, Monteverde and Teece (1982) have shown that Ford and General Motors have adopted a pattern of vertical integration, which fits into the legal-institutional environment of the United States and which protects rents from the firms' knowledge-base, like specialized human capital or patents. In Japan car manufacturers have adapted to another pattern of vertical integration, whereby a different culture of industrial relations, which is based on trust, protects the firms' knowledgebase. The important insight of this study is that governance modes are path dependent and they co-evolve together with their institutional environment. 
Thereby different combinations of corporate governance and regulation may attain equal levels of efficiency. With respect to incentive channeling on energy markets one can conclude from this study that it is highly likely that there will be not only one way, in order to facilitate incentive channeling, but depending on the unique institutionalization and history of energy markets in each country the appropriate regulatory measures may vary.

It is apparent that transaction cost economics seemingly has a lot to contribute to the understanding of the interrelation between corporate governance and the regulation of energy firms, as well as to the appropriate design of corporate governance and regulations of the energy sector. Amazingly enough, public policy has remained by and large unaffected by the insights of transaction cost economics. This appraisal has been underpinned by Paul Joskow (1991, p. 77): "However, while transaction cost economics has played a role in the debates about vertical restructuring in these industries, and the precise form that such restructuring should take, it is my sense that the direct role of transaction cost considerations in influencing the direction of public policy has, so far, been quite modest."

In order to analyze the behavior of agents in vertically integrated energy firms or unbundled grid firms in more detail, one can ask whether the processing of external incentives through the corporate governance of regulated firms is different from that of firms in unregulated markets. An important difference between the two kinds of firms exists with regard to their selection environment. Under the conditions of workable competition, market forces select firms. If a firm cannot satisfy the preferences of consumers, it has to face bankruptcy (Alchian 1950). That is, incentives are going straight from consumers via the corporate veil to decisionmaking agents. These market-driven incentives are high-powered and lead to an efficient outcome. In other words, in order to survive competition, firms will have to adapt corporate governance structures which lead to a minimization of transaction costs. As a result, firms may experiment with new forms of corporate governance or may institutionalize a sort of corporate culture that supports the channeling of incentives. The decentralized discovery procedure of competition (Hayek 2002) automatically reveals which firms have the best ideas in order to tackle the problem of incentive channeling (Kole and Lehn 1997, 1999; for a recent survey of the literature see Love 2010).

In regulated markets, there is no such automatism. Instead, the regulator artificially forms the selection environment by granting monopoly and simultaneously regulating prices and quality. The point is that consumers cannot freely choose between different products and services but have to take the offers that have been pre-specified by the regulator. This implies an important consequence: While in ordinary markets, firms have to look at the preferences of consumers, the regulated firm looks at the statutory requirements and tries to capture the regulator (Mueller 2004; Peltzman 1976; Etzioni 2009). A financial analyst has aptly pictured this concept: "When you buy the securities of a utility, you're buying the public utilities commission" (Business Week 1979, p. 114). To put it another way, there is a close relationship between the regulator and the regulated firm, and it seems plausible that this sort of embeddedness of the regulated firm in the framework of regulation makes a strong imprint (Stinchcombe 1965; Johnson 2007) on the formal 
and informal governance of regulated firms. For example, studies of the US electricity industry have shown that tight regulatory oversight leads to a more formal organization of electricity firms, reduced entrepreneurial initiative and paternalistic working relationships (Russo 1992). One might argue that the mindset of the public regulation authority is copied into the organizational routines of the regulated firm.

However, imprinting has another effect that is as important as the transfer of organizational routines from the regulator to the regulated firm. Organizational routines are often persistent or path-dependent (Nelson and Winter 1982; Narduzzo and Warglien 2008; Russo 1992). That is, one cannot easily switch from one mode of corporate governance to another or intensify incentives in order to promptly develop an efficient output of regulated firms. For example, if a public utility has no performance-based career system, such a career system will not emerge overnight. Instead, there will be a period of transition before external incentives become mirrored by organizational routines and external incentives can pass through corporate governance structures.

The implementation problem is non-existent in neoclassical economics. However, the imprinting, institutionalization and path dependence of organizational routines are important building blocks for a better understanding of the working of external incentives in the corporate governance structures of regulated firms (for a general discussion see Santos and Eisenhardt 2005).

In summary, in energy markets it cannot be assumed that the corporate governance structures of firms adapt automatically to the transaction cost minimal solution. On the contrary, the market failure of natural monopoly is mirrored in the governance structure of either power grid firms or vertically integrated energy firms. From this follows that the regulation of energy markets involves both external and internal regulation, as well as the complementary fine-tuning of external and internal regulations. Thereby a division of labor between different theoretical branches is looming: (1) Neoclassical economics yields insight into the kind and degree of market failure, as well as which part of the supply chain of energy firms contains market failure; (2) transaction cost economics informs about the efficient design of vertical coordination between the different parts of the supply chain and highlights potential conflicts with antitrust issues; and (3) theories of organizational behavior produce a nuanced account of the motives and attitudes of decisionmaking agents within given corporate governance structures. While in the previous chapters neoclassical economics and transaction cost economics were center stage, the next chapter will highlight insights from organizational behavior and New Sociological Institutionalism.

\subsection{Looking inside the "black box": the working of incentive regulation within energy firms}

The corporate actor framework makes it possible to combine insights from New Institutional Economics with New Sociological Institutionalism by thinking of firms as constitutional contracts of individual actors, which are constrained by external regulations. Thereby the constitutional contract of the firm builds up the firm's 
corporate governance. However, the constitutional contract is incomplete and leaves room for individual decisions of agents, who may behave not in accordance with rational choice theory. In addition, there may be informal rules in play, which are not embraced by formal rules of corporate governance and which cannot be changed easily by will, but are subject to larger processes of societal and cultural development.

External regulation, like incentive regulation, has to take into account both, the consequences of the incompleteness of the firm's constitutional contract as well as the existence of informal rules, which may belong to the firm level (corporate culture) as well as to the level of whole societies. In the following this will be elucidated in more detail by highlighting some important problems, which have been until now largely neglected in the literature on incentive regulation. The aim is to set up a research agenda, which pops up when the "black-box" of energy firms is opened.

\subsubsection{Clarity and comprehensibility of incentives}

It can be assumed that incentive schemes work more properly if the targeted results are well defined and the causal link between incentives and the subsequent (re)actions of energy firms are verifiable. Verification as an important ingredient of incentive schemes on energy markets is in accordance with findings in research on organizational behavior and social psychology (Kahneman et al. 1982; London 2003; Léon 1997) as well as in New Institutional Economics (Furubotn and Richter 2005; Ritz and Sager 2010). That is, even if the relation between the regulator and the regulatee is complex and outcomes are opaque, all kinds of behavior control should be complemented by a sort of outcome control (Verma et al. 1999; Eisenhardt 1985). The reason is that clear-cut defined regulatory outcomes, or at least verifiable outcome proxies, may help to prevent a subtle deviation from the initially defined regulatory aims. Such deviations are likely because the sometimes strong ties between the regulator and the regulated firms may allow energy firms to influence the regulator and to obtain relaxations of initial regulations. For example, former managers of energy firms frequently become members of the regulation authority. This allows former managers to thwart regulation and to conserve the monopoly profits of energy firms (Knittel 2006). This "regulatory capture" (Stigler 1971) may be prevented if the aims of regulation are made transparent and verifiable by the public.

Another point is that incentives should be straightforward and comprehensible (Pfeifenberger and Tye 1995). This requirement, again, is in line with findings in research on organizational behavior and social psychology (Kahneman et al. 1982; Léon 1997). Straightforwardness and comprehensibility are important ingredients of incentive schemes because the recipients of incentives will more easily adapt to those incentives. That is, only if the regulatee understands the workings of the incentive scheme will he be able to respond properly and fulfill the aims of regulation. In addition, a plain and clear-cut incentive scheme is also advantageous for the regulator, because it is easier to control energy firms if the yardstick of regulation is not ambiguous and subject to different interpretations. However, at first 
glance, from the perspective of New Sociological Institutionalism, this seems not to be evident. Straightforwardness and comprehensibility is seen more as a sort of rationalized procedure that creates the image of rational choices rather than the reality. Or, to put it in the words of Meyer and Rowan (1991, p. 53): “... organizational success depends on factors other than efficient coordination and control of productive activities." Thus, the emphasis placed by rational-choice theorists on formal procedure as a means to produce more rational decisions becomes undermined by New Sociological Institutionalism. However, New Sociological Institutionalism does not completely disregard technical efficiency. In case that organizational output is easily measurable, when productive technologies are well defined, and when criteria of success are unambiguous, then technical efficiency matters (Carruthers 1995). In this respect Meyer and Rowan (1991) explicitly mention public utilities, and one may conclude that a straightforward and comprehensible design of incentive regulation is also a worthwhile aim from the perspective of New Sociological Institutionalism.

Clarity and comprehensibility of incentive schemes seem to be evident or even trivial requirements of incentive regulation. However, in reality, these requirements are frequently ignored (Pfeifenberger and Tye 1995; Buechner and Katzfey 2006). For example, the British regulation of electricity grid firms employs an incentive formula that aims to considering numerous characteristics of grid firms in order to determine the optimal incentive. The formula is supposed to establish optimal incentives for grid firms, leading to an increase in productivity. In addition, the formula aims to cover the costs of running the grid and ensuring a secure supply of energy (for the complete formula, see OFGEM 2008).

Every term in the formula for the British "revenue cap" has its justification and has been discussed at length in academic and political circles, as well as by the scientific board of the OFGEM (Office of Gas and Electricity Markets). However, one can ask whether the complexity of the formula and the manifold data needed to feed the formula may thwart the aim of setting optimal incentives and achieving efficient regulatory outcomes. What is still missing in the debate on incentive regulation is a more detailed discussion of other straightforward instruments of incentive regulation. Those other instruments of incentive regulation may not be as sophisticated as the current incentive schemes, yet these other incentive schemes might be highly effective (for an early statement see Pfeifenberger and Tye 1995).

A strong candidate for such a clear-cut and comprehensible instrument is the length of the regulation period. The longer the regulation period, the stronger is the incentive for cost reduction, as energy firms have a longer amount of time to capture the difference between the price ceiling (price or revenue cap) and the true costs (Joskow 2006; Baumol and Klevorick 1970; Vogelsang 2002). For example, statistical estimations for Austrian grid firms point to a sharp increase in the incentive to reduce costs when the regulation period is extended from 5 to 10 years. If the regulation period is 5 years, then there is an incentive to reduce costs by about $28 \%$, while a regulation period of 10 years produces an incentive to reduce costs of about 49\% (Groenli and Haberfellner 2002). Therefore, it may be advantageous to grant longer regulation periods and simultaneously to simplify the regulation 
formula in order to have a more focused incentive to reduce costs. In addition, this may block opportunities for energy firms to bargain for cost categories, which are exempted from incentive regulation. That is, the aim of incentive regulation becomes much clearer, and energy firms have a strong impetus to pass incentives through the corporate governance structure.

Finally, it is interesting that the European Commission has recently taken steps which aim at an improvement of clarity and comprehensibility of regulation by drafting a proposal on energy market integrity and transparency (European Commission 2010). Even though this proposal is not directly concerned with incentive regulation, it is stated in this paper that "citizens, business and authorities must have confidence in the integrity of these wholesale energy markets" (European Commission 2010, p. 2). For this aim the Agency for the Cooperation of Energy Regulators (ACER), which has been newly founded (EC No 713/2009), will collect relevant data of energy markets and make them centrally available for the public. In addition, under the heading "Clear and consistent rules" the proposal states that the clearness and consistency of the ruling against abusive market practices are important aims of energy regulation. However, the future will reveal, if these intentions of the Commission become implemented by the national regulators and whether the clarity and comprehensibility of regulation will be improved.

\subsubsection{Incentive compatibility}

Another important point on the research agenda is compatibility between the "external" incentives of energy regulation and the aims of decision-makers "within" the firm. Two examples may clarify the importance of incentive compatibility:

1. "Legal Unbundling" commands a governance structure that grants managers of grid firms a widely unaffected management of the grid. The underlying idea is that managers of grid firms should care about the efficient supply of grid services and should not discriminate between the different customers of the grid (Brunekreeft and Ehlers 2006). That is, incentive compatibility requires that parent companies of grid firms do not interfere into the decisionmaking of grid firms - for example, into the allocation of grid capacity or investments in the grid. To put it simple, under a legal unbundling regime, corporate governance must shield grid firm managers against the direct or indirect intervention of parent companies. This legal shield against interventions has to be rather strong, because market forces do not automatically correct undue interventions by parent companies. In normal markets, undue interventions by a parent company into the operations of an affiliated company may lead to the bankruptcy of the affiliation, whereas in regulated markets, those interventions may only result in a loss of efficiency-the monopoly position will secure profits anyway.

2. Incentive compatibility demands that decision-makers can satisfy their individual preferences and reach their goals within the constraints of corporate 
governance structures. If external regulation does not respect individual preferences, then regulation may produce unintended consequences (Verma et al. 1999). For example, under a "legal unbundling" regime, the career of a grid manager may depend on the manager's contribution to the overall profit of the holding company. However, if there is the legal obligation to give nondiscriminatory access to the grid for competitors of the holding company, then the manager of the grid firm faces a severe trade-off. On the one hand, the manager may comply with regulation, taking into account the possibility that his career may deteriorate. On the other hand, the manager can apply sophisticated tools of discrimination in order to derogate the competitors of the holding company, which may increase his career chances but may also expose him to the risk of being punished by the regulator. To be clear, whether grid managers decide on one or the other option depends on a multitude of factors, but the trade-off points again to the crucial interdependence of corporate governance and external regulation when one means to regulate energy firms effectively.

In order to attain incentive compatibility between "external" regulations and the goals of managers one has to design the corporate governance of grid firms adequately. An appropriate economic tool box for shaping corporate governance and to align the goals of regulation and the goals of managers is provided by "mechanism design" (Groves and Ledyard 1987), which in recent years has got a lot of attention for a proper regulation of energy markets (Silva et al. 2001; Battle and Perez-Arriaga, Batlle and Perez-Arriaga 2008). The idea is to "manipulate" the institutional environment of managers in a way that they behave in a manner that is compatible with the aims of regulation. However, mechanism design relies strongly to the assumption of rationality and selfishness of agents (Groves and Ledyard 1987), which may be seen as an obstacle to applying this concept to real world problems, when agents often deviate from rational behavior (McFadden 2009). Therefore it is useful to analyze the problem of incentive compatibility also from the perspective of New Sociological Institutionalism, which does not rely on the rationality assumption. From that perspective an agent will align the goals of regulation with his own goals, if there is sense-making possible (Weick et al. 2005). Sense-making is possible, if the agent can attribute to regulations, corporate governance or other institutions an inherent logic and legitimacy as well as he can link his experience to the challenges of regulation. If institutional settings make sense, then the agent is more willing to accept regulations and to adapt his behavior to the logic of institutional constrains. For example, incentive regulation may be obeyed more easily, if the regulation scheme makes sense not only from the perspective of cutting the costs of the power grid, but also if incentive regulation is in accordance with environmental protection and if cutting costs does not threat the jobs in the energy sector.

As it turns out, New Sociological Institutionalism may be a helpful tool to get deeper insight into the sense-making of energy regulation, if the proper behavior of managers depends on the concerted interplay between "external" regulations and corporate governance. 


\subsubsection{Magnitude and reliability of incentives}

Managers of grid firms will be more likely to comply with regulations if the magnitude of regulations is strong and if regulations are reliable. This proposition is intuitive and has been recently proved by experimental studies of mechanism design (McFadden 2009).

The design of corporate governance has a significant effect on the magnitude of regulatory incentives because corporate governance rules decide, which incentives are eligible and which are not. For example, under a regime of "legal unbundling" the regulator may decide that the profits of the grid firm have to be reinvested into the power grid and should be not transferred to the parent company. Such a legal obligation diminishes the incentive to disinvest into the grid and to lower the net capacity, while it strengthens the incentive to allocate the capacity of the power grid efficiently. Or, the regulator might forbid bonus wage systems for power grid firms, which are linked to the overall profit of the parent company. That is, grid managers should not indirectly profit from discrimination against competitors. If a bonus wage system is installed, then it seems to be more reasonable for that system to refer to the increase in productivity of grid firms per period. In that case, it is more likely that incentives become properly channeled through the corporate body of grid firms.

Under a regime of "ownership unbundling" the incentive for managers of grid firms to disinvest into the power grid may be even higher, in order to obtain-at least for a short term-a high rate of return. Therefore, even stronger legal obligations seem to be in order to counterbalance the incentive to disinvest into the grid capacity. Also the bonus wage system should not refer to the rate of return of the grid firm, because that would incentivize disinvestment. Otherwise, discrimination between suppliers of energy seems to be no problem under a regime of "ownership unbundling".

It becomes clear that the design of corporate governance leads to different weights of the various incentives that are in play, and that the regulator has to pick appropriate regulations which press grid managers to behave in accordance with the aims of regulation.

The reliability of regulations is also of great importance to the targeting of incentives (Stern 1997; Hall et al. 2000). This point entails several aspects. The first is that incentives have to be enduring and must be repeated so that decision-makers can adapt their behavior. The second is that incentives must not be subject to renegotiations. That is, managers should make an effort to adapt their behavior and not attempt to manipulate regulations. The third aspect is that rewards from regulatory compliance must follow promptly, in order to underscore the causal link between regulatory compliance and rewards.

The magnitude and reliability of incentives mirror a well-known pair of parameters in economics that has especially been applied in the economic theory of crime (Becker 1968). The first is the level of punishment, and the second is the likelihood of detection. While the magnitude of the incentives may be interpreted as the level of punishment, the reliability of the incentives can be interpreted as the likelihood of one's becoming detected in committing a crime. The stronger the magnitude of the incentives and the higher the reliability of the regulation, the more 
compliance with regulation can be expected. Even if one is of the opinion that organizational behavior is not the result of such a simple calculus, the magnitude and reliability of incentives are important parameters for the design of corporate governance of grid firms. In addition, it seems that different mixes of magnitude and reliability of incentives may yield in the end the same regulatory result.

However, one can ask whether New Sociological Institutionalism can add insights to the interplay of governance structures and the magnitude and reliability of regulation of grid firms. In this regard an important argument is coined by DiMaggio and Powell (1983, p. 152). They hold that organizations "tend to model themselves after similar organizations in their field that they perceive to be more legitimate or successful." That is grid firms may adapt their organizational structure in response to corporate governance rules and certain regulations, however the realized organizational form may be not the result of a firm's considerations how to improve its economic efficiency. The organizational form may be more influenced by "mimetic" processes that focus on well established and legitimized organizational routines and structures of an industry. If that argument by DiMaggio and Powell were true, then aspects of organizational legitimization must be taken into consideration, when one is out to determine the efficient mix of the magnitude and reliability of incentives. For example, bonus wages which are linked to the overall profit of the parent company may lead to economically inefficient behavior of grid managers. However, this sort of bonus wage system may be seen as the legitimate one, and to forbid this system may provoke counter actions of managers, in order to circumvent the prohibition. That is New Sociological Institutionalism points out that a sort of "command and control" regulation has limitations, if it is not embedded into an organization's social context.

\subsubsection{Authorization}

Managers have to be authorized to take all appropriate measures in order to react to incentive regulation in a coordinated manner. For example, under a regime of incentive regulation grid managers have to decide on two important things: (1) The access price for using the grid and (2) the budgeting of investments into the grid. It is obvious that these two tasks are highly interrelated. The access price, in combination with the grid capacity, determines the potential profit of the grid firm. On the other hand, the grid capacity depends on the investments into the grid. Therefore, the management of access prices and investments into the grid should be bundled as part of the same division, in order for there to be integrated management of grid capacities and access prices. In addition, this sort of integrated management points to the need for a fine-tuned accounting system that mirrors the requirements of incentive regulation on the one hand and provides all information necessary for the management to react in a concerted way on the other.

If the authority to react to incentive regulation is split (for example, if the planning of investments into the grid occurs in the finance division while the determination of access prices occurs in the sales division) there may occur severe frictions, which complicates proper reaction to incentive regulation. The external incentive will be diffused in the corporate governance structure of grid firms, and 
incentive regulation may provoke contradictory reactions. The finance division may plan for an extension of the net capacity, while the sales division may plan with a constant net capacity. Although it is somewhat overstated, this simple example makes clear that the allocation of authority plays a crucial role not only in the proper processing of incentive regulation in corporate governance structures but also in deriving a consistent strategy for how to react on incentive regulation.

Therefore it seems pretty clear that grid firms should strive for an allocation of management tasks, which leads to a concerted management of activities. Regulation should avoid that a proper managerial planning of the power grid becomes hampered. This requirement is by no means trivial as the case of "accounting unbundling" shows. One can certainly imagine economically efficient modes of "accounting unbundling". However, in practice it is not sure that those systems become implemented. This may trace back to opportunistic actions of agents, but may be also explained by processes of institutionalization of corporate governance: Energy firms may adapt to that sort of internal accounting system which has the greatest legitimacy in the energy sector, irrespective of the consequences for economic efficiency.

\subsubsection{Legitimacy}

As already mentioned legitimacy plays an important role in the implementation of incentive schemes. By the term "legitimacy" in general is meant a procedural quality of corporate governance that relates to democratic accountability (participation), the separation of powers, transparency, and the rule of law (Coglianese 2007). That is, an organization is seen as legitimate if it is in accordance with the basic principles of the social organization of men, or, in terms of New Sociological Institutionalism: Corporate governance is legitimate if it is embedded in the larger institutional context of societal living (Aguilera and Jackson 2003; Granovetter 1985 ) and if there are no contradictions between societal and organizational rules. Legitimacy does not have to be in conflict with economic efficiency. However, there can be conflicts if organizational rules enforce efficient behavior but this sort of behavior is not in accordance with the moral frame or accepted routines of society. In such a case, efficient behavior is seen as illegitimate.

The point is that economic consequences of incentive regulations that are regarded as illegitimate may provoke organizational behavior that runs against the proper working of incentive regulation. A good illustrative case can be found in Germany. In the past, German energy firms were quasi state-owned by the German federal states (like, for example, Bavaria or Saxony) and local communities. However, after the deregulation of the energy markets, there still exists strong engagement in energy firms on the part of the German federal states, which are holding large shares of equity. Additionally, often boards and other committees are staffed with (former) politicians. Therefore, there is still a high degree of direct and indirect political influence on energy firms in Germany such as RWE or EON.

In the past, German energy firms granted ample extra benefits to their employees, like high wages, generous pension plans, broad social security programs, child care for children of employees, etc. In addition, energy firms supported communal events 
like music festivals or sporting events. With the advent of the deregulation of the energy sector and the beginning of incentive regulation, all these extra costs have come under scrutiny because such costs are not directly related to the production, distribution and sale of energy. However, cutting these extra costs is regarded as illegitimate by workers and other beneficiaries, like local communities, because these extra benefits are seen as social achievements that are important components of worker-oriented and democratic firms (Mitbestimmung 2006). Therefore, labor unions and shareholding communities exert pressure on executive managers via the board to preserve these extra-social benefits by emphasizing the corporate social responsibility of energy firms.

Also in New Zealand legitimacy played a role, when (local) grid firms which are owned by consumer trusts, were exempted from incentive regulation. It was said, that in case of trust ownership all benefits will accrue automatically to consumers. In addition, it was assumed that consumers will feel responsible for a proper working of management. That is consumers can directly participate in a grid firm's decisions and the management is directly accountable to consumers. Hence a redundant control of those grid firms by the regulator was seen not only to be unnecessary, but an additional layer of regulation was considered as illegitimate (Lewis and Meade 2007). However, today also trust owned grid firms are subject to incentive regulation, which has triggered a public debate about the legitimacy of the regulator's interventions.

In general, legitimacy points to the important fact that besides efficiency also other normative considerations play a role, if one is out to regulate an industry. Disregarding legitimacy issues may hamper the proper implementation of incentive regulation severely.

\subsubsection{Corporate culture}

Corporate culture and work attitudes also play an essential role in the effectiveness of incentive channeling. In the past, energy firms were seen as vertically integrated natural monopolies that were coordinated mostly by the commands of civil servants. The influence of civil servants had a strong imprinting effect on the corporate culture of energy firms, which adopted a corporate culture very similar to that of the regulating bureaucracy (Russo 1992).

The interconnection of energy firms with the regulating body put forth a sort of corporate culture less oriented to the needs of consumers, but to the needs of politics. In addition, corporate culture of energy firms does not regard competition as an important part of a market economy but instead is strongly adapted to the accuracy of bureaucratic procedures (DiMaggio and Anheier 1990). Therefore, incentive regulation must cope with a corporate culture that processes incentives not like a market, but like a bureaucratic sub-unit. In addition, in the past, key positions of energy firms were occupied by engineers who were more interested in a secure supply of energy than in cutting costs. As a consequence, the changes to more market-oriented regulation have often been hampered by engineers in management positions (Mueller and Carter 2007). The bureaucratic culture of energy firms has been amplified in the past by the application of cost-plus regulation. Cost-plus 
regulation has led to a situation in which energy firms could not make any profits but also would not see any losses. That is, profit-making did not have the same importance in the energy industry that it did in other industries, or else it was not seen as relevant at all. This situation had a lasting imprinting effect on the corporate culture of energy firms, too (DiMaggio and Anheier 1990). A grid firm, which is not profitable under incentive regulation, may not be put under pressure to become more efficient, because the management of the parent company may "forgive" the management of the grid firm. Managers of parent companies of grid firms are more likely to forgive inefficiencies, because they often contain the old routines of costplus regulation within themselves (Russo 1992), although cost-plus regulation has come to an end.

In sum, corporate culture and work attitudes constitute a set of important but complex problems that are of the utmost importance when one is aiming to make incentive regulation work. Even if one is of the opinion that, in the end, the corporate culture of energy firms will converge towards that of firms in ordinary markets, the corporate culture of energy firms represents a set of special problems that have to be overcome in the transition period from highly regulated markets to deregulated ones. Although it is intuitively clear that culture in general as well as corporate culture in particular play an eminent role for the proper implementation of incentive regulation, the economics approach is not well equipped to integrate cultural reasoning into its considerations (for a recent discussion see for example Guiso et al. 2006, 2009). One of the problems of the economics approach is the insufficient integration of history (North 1990; David 1985; DiMaggio and Anheier 1990), which plays an important role for the transformation of regulatory regimes. The approach of New Sociological Institutionalism can contribute to a better understanding of the cultural embeddedness of energy regulation by highlighting the historical path of regulations (DiMaggio and Anheier 1990).

\section{Summary}

This paper is an attempt to achieve more insight into the complex interplay between "external" market regulations and the "internal" regulations of firms. At first glance, the relation between external and internal regulations seems trivial because it is clear that there is such a relation and firms are well-advised to make adaptations to corporate governance structures based on external regulations.

On a conceptual level, the relation between external and internal regulations is not really problematic as long as firms are operating in markets without market failures. Firms that are not able to adapt their organizational structures and modes of corporate governance to external regulations will face bankruptcy. That is, in markets without any severe failures, market processes work on both levels: There will be efficient allocation of products on the market level as well as efficient allocation of resources on the firm level. Thereby, market incentives will be automatically channeled to the decision-making agents of firms. To be fair, all firms may face serious problems in adapting their internal processes. However, in competitive markets, there is always a pool of experimenting firms trying to isolate 
those adaptations, which will bring forth viable governance structures for the adequate channeling of incentives. The evolutionary process of variation, selection and retention ensures that corporate governance adapts to external regulations and that incentive channeling will be workable. Therefore, from a macro perspective, the interplay between external and internal regulations has not received much attention in the past (Kole and Lehn 1997, 1999).

However, the need to understand in which way external and internal regulations interact increases sharply if the automatic processing of external incentives through the corporate governance structure of firms becomes systematically blocked. That happens when there is no pool of firms competing with differentiated products and different corporate governance structures but there instead exists a natural monopoly. This has substantial consequences for the workability of incentive channeling because now the regulator must consider the negotiation between external and internal regulations.

In recent years, many countries have deregulated incumbent energy monopolies and introduced new modes of regulation like incentive regulation. However, the new incentive schemes are not an unmitigated success story (Verma et al. 1999). A major problem seems to be the neoclassical framework that is imposed on the analysis of energy markets. This is not to say that the neoclassical analysis of energy markets is futile; however, it must be complemented by other theoretical approaches.

It turns out that there are two restrictions of neoclassical analysis that are of great importance, when one is aiming to make incentive regulation workable. The first is the widely held "black box" view of firms. The second is the idea that agents always make rational choices. Rational choice is a model of human action that can be easily connected to welfare economics. That is, neoclassical theory allows normative statements that are logically consecutive and coherent, but this sort of analysis becomes dubious if it cannot adequately reflect reality (Schotter 1996).

One may discuss at length whether rational choice models can reflect reality well enough, in order to derive meaningful propositions. However, in this paper it is argued that it is useful to complement rational choice analysis with insights of organizational behavior and New Sociological Institutionalism, in order to achieve a more nuanced picture of the interrelationship between external and internal incentives.

To make this point more accessible, a research agenda has been presented for the analysis of incentive channeling in energy markets. The research agenda highlights several aspects of energy market regulation that cannot be processed using neoclassical theory alone.

The presented research agenda is by no means conclusive; there may be other points that are also of interest for a better understanding of incentive channeling, or the points of the research agenda may be subdivided for specialized research questions. A more specialized research agenda might be necessary if one is out to empirically test hypotheses concerning the channeling of incentives. For example, from the perspective of New Sociological Institutionalism it is questioned that straightforwardness and comprehensibility of incentives are ingredients for improving rational decision making in organizations. Otherwise, in New 
Sociological Institutionalism it has been hypothesized that in case that organizational output is easily measurable technical efficiency may play a role for organizational design. Public utilities are explicitly mentioned in this regard (see Sect. 4.2.1). For that reason it seems worthwhile to test empirically whether straightforwardness and comprehensibility of incentives do play a role for a proper incentivizing of grid firms, and if that is the case to what degree. A conclusive answer to this question would imply important theoretical as well as policy relevant insights. On the theoretical level the meaning of organizational rationality could be further clarified, which is a topical question in New Sociological Institutionalism (Beckert 2010). On the policy level one would gain more insight in how to design exactly the regulatory and institutional infrastructure of incentive regulation, in order to make the targeting and channeling of incentives through the organizational structure of grid firms more precise.

Another subsequent step could be the application of the proposed framework on a specific country and to derive from this "case study" a refinement of the framework. In particular, this sort of study would allow for a better understanding of the institutional dynamics of incentive regulation. That is, a case study would yield insights about the changes of a country's mode of incentive regulation with regard to the dimensions indicated by the proposed research agenda. The value of such a study is apparent. If systems of incentive regulation adopt over time automatically those governance modes which improve incentive channeling, then one may conclude that contemporary systems of incentive regulation may be yet not optimal, but are at least heading towards more efficiency. Otherwise, if those improvements do not take place over time, then governments may consider more vigorously the purposeful improvement of incentive channeling along the proposed research agenda. For example, recently in the United Kingdom a 2 year review of its system of incentive regulation has been completed (RIIORevenue $=$ Incentives + Innovation + Outputs model $)$, which provides ample material about how energy regulation has been targeted on energy firms in the last years and how its focus shall be sharpened in the future (e.g. OFGEM 2010). In this regard it is interesting that the RIIO-review proposes refined output measures for a proper cost assessment of grid firms, which are intended to be more accessible for shareholders and the public as well as more operational for management. This is broadly in line with the here proposed improvements of incentive regulation.

In the end the proposed framework may be understood as a first step toward a better understanding of the crucial relationship between external regulations and corporate governance in the case of public utilities, where the market process does not automatically guarantee the proper channeling of incentives. The presented insights may also be of interest for the regulatory body, which is interested in carefully targeted incentive regulation. Furthermore, energy firms themselves may be interested in the findings, which could help them make insightful adjustments to their corporate governance under an incentive regulation regime. 
Open Access This article is distributed under the terms of the Creative Commons Attribution Noncommercial License which permits any noncommercial use, distribution, and reproduction in any medium, provided the original author(s) and source are credited.

\section{References}

Acton, J., \& Vogelsang, I. (1989). Introduction to "Symposium on Price-Cap Regulation". Rand Journal of Economics, 20, 369-372.

Aguilera, R. V., \& Jackson, G. (2003). The cross-national diversity of corporate governance: Dimensions and determinants. Academy of Management Review, 28, 447-465.

Alchian, A. A. (1950). Uncertainty, evolution and economic theory. Journal of Political Economy, 58, 211-221.

Alchian, A.A., \& Demsetz, H. (1972). Production, information costs, and economic organization. American Economic Review, 62, 777-795.

Armstrong, J. S. (1978). The manager's dilemma: Role conflict in marketing. In G. Fisk, J. Arndt, \& K. Gronhaug (Eds.), Future directions for marketing (pp. 78-89). Cambridge, MA: Marketing Science Institute.

Batlle, C., \& Perez-Arriaga, I. J. (2008). Design criteria for implementing a capacity mechanism in deregulated electricity markets. Utilities Policy, 16, 184-193.

Baumol, W. J. (1959). Business behavior, value and growth. New York: Macmillan.

Baumol, W. J., \& Klevorick, A. K. (1970). Input choices and rate-of-return regulation: An overview of the discussion. Bell Journal of Economics and Management Science, 1, 162-190.

Becker, G. (1968). Crime and punishment: An economic approach. Journal of Political Economy, 76, $169-217$.

Beckert, J. (2010). Institutional isomorphism revisited: Convergence and divergence in institutional change. Sociological Theory, 28, 150-166.

Berger, P. L., \& Luckman, Th. (1966). The social construction of reality: A treatise in the sociology of knowledge. New York: Doubleday.

Blackmon, G. (1994). Incentive regulation and the regulation of incentives. Boston: Kluwer.

Braeutigam, R. R., \& Panzar, J. C. (1993). Effects of the Change from Rate-of-Return to Price-Cap Regulation. American Economic Review, Papers and Proceedings, 83, 191-198.

Brunekreeft, G. (2002). Regulation and third-party discrimination in the german electricity supply industry. European Journal of Law and Economics, 13, 203-220.

Brunekreeft, G., \& Ehlers, E. (2006). Ownership unbundling of electricity distribution networks and distributed generation. Competition and Regulation in Network Industries, 1, 63-86.

Buechner, J., \& Katzfey, J. (2006). Die Wirkung der Anreizregulierung in der Praxis. Zeitschrift fuer Energie, Markt, Wettberb, 6(2006), 44-47.

Business Week. (1979). A dark future for utilities. May, 28, 114.

Campbell, J.L., \& Lindberg, L.N. (1990). Property rights and the organization of economic activity by the state. American Sociological Review, 55, 634-647.

Carruthers, B. G. (1995). Accounting, ambiguity, and the new institutionalism. Accounting, Organizations and Society, 20, 313-328.

Coglianese, C. (2007). Legitimacy and corporate governance. Delaware Journal of Corporate Law, 32, $159-167$.

Coleman, J. S. (1974). Power and structure of society. New York: Norton.

David, P. A. (1985). Clio and the economics of QWERTY. American Economic Review, Papers and Proceedings, 75, 332-337.

DG Competition. (2007). Report on energy sector inquiry. SEC (2006) 1724.

DiMaggio, P. J., \& Anheier, H. K. (1990). A sociological conceptualization of non-profit organizations and sectors. Annual Review of Sociology, 16, 137-159.

DiMaggio, P. J., \& Powell, W. W. (1983). The iron cage revisited. Institutional isomorphism and collective rationality in organizational fields. American Sociological Review, 48, 147-160.

Downs, A. (1957). An economic theory of democracy. New York: Harper.

Easterbrook, F. H., \& Fischel, D. R. (1991). The economic structure of corporate law. Cambridge, Mass.: Harvard University Press.

Eisenhardt, K.M. (1985). Control: organizational and economic approaches. Management Science, 31, 134-149. 
Etzioni, A. (2009). The capture theory of regulations-Revisited. Society, 46, 319-323.

European Commission. (2010). Proposal for a regulation of the european parliament and of the council on energy market integrity and transparency, summary of the impact assessment. SEC (2010) 1510 final.

Eurostat. (2006). Gas and electricity market statistics, Data 1990-2006. Eurostat Luxembourg.

Festinger, L. (1957). A theory of cognitive dissonance. Evanston: Peterson.

French, J., \& Raven, B. H. (1959). The bases of social power. In D. Cartwright (Ed.), Studies in social power (pp. 150-167). Ann Arbor: Institute for Social Research.

Farber, D. A., \& Frickey, P. P. (1991). Law and public choice. A critical Introduction. Chicago: Chicago University Press.

Furubotn, E. G., \& Richter, R. (2005). Institutions and economic theory (2nd ed.). Ann Arbor: University of Michigan Press.

Goerten, J., \& Clement, E. (2006). Electricity prices for EU households and industrial consumers on 1 January 2006. Statistics in focus (Eurostat), No. 11.

Granovetter, M. (1985). Economic action and social structure: The problem of embeddedness. American Journal of Sociology, 91, 481-510.

Granovetter, M. (2005). Business groups and social organization. In N. Smelser \& R. Swedberg (Eds.), Handbook of economic sociology (2nd ed., pp. 429-450). Princeton, NJ: Princeton University Press and Russell Sage Foundation.

Groenli, H., \& Haberfellner, M. (2002). Mechanismen der Anreizregulierung, E-Control (Vienna) Working Paper, No. 5.

Groves, T., \& Ledyard, J. (1987). Incentive compatibility since 1972. In T. Groves, R. Radner, \& S. Reiter (Eds.), Essays in honor of Leonid Hurwicz (pp. 48-111). Minneapolis: University of Minnesota Press.

Guiso, L., Sapienza, P., \& Zingales, L. (2006). Does culture affect economic outcomes. Journal of Economic Perspectives, 20, 23-48.

Guiso, L., Sapienza, P., \& Zingales, L. (2009). Cultural biases in economic exchange? Quarterly Journal of Economics, 124, 1095-1131.

Hall, C., Scott, C., \& Hood, C. (2000). Telecommunications regulation. London and New York: Routledge.

Hansmann, H. (2006). Corporation and contract. American Law and Economics Review, 8, 1-19.

Hayek, F. A. (2002). Competition as a discovery procedure. Quarterly Journal of Austrian Economics, 5 , 9-23.

Jensen, M. C. (2001). Value maximization, stakeholder theory, and the corporate objective function. Journal of Applied Corporate Finance, 14, 8-21.

Jensen, M. C., \& Meckling, W. H. (1976). Theory of the firm: Managerial behavior, agency costs and ownership structure. Journal of Financial Economics, 3, 305-360.

Johnson, V. (2007). What is organizational imprinting? Cultural entrepreneurship in the founding of the Paris opera. American Journal of Sociology, 113, 97-127.

Joskow, P. L. (1991). The role of transaction cost economics in antitrust and public utility regulatory policies. Journal of Law, Economics and Organization, 7, S53-S83.

Joskow, P. L. (2006). Incentive regulation in theory and practice: electricity distribution and transmission networks. MIT Working Paper, January 21, 2006.

Kahn, A. E. (2002). The deregulatory tar baby: The precarious balance between regulation and deregulation, 1970-2000 and henceforward. Journal of Regulatory Economics, 21, 35-56.

Kahneman, D., Slovic, P., \& Tversky, A. (Eds.). (1982). Judgment under uncertainty: Heuristics and biases. Cambridge, Mass: Cambridge University Press.

KEMA-report. (2005). Review of European electricity prices. Bonn: KEMA consulting.

Knieps, G. (2006). Sector-specific market power regulation versus general competition law: Criteria for judging competitive versus regulated markets. In F. P. Sioshansi \& W. Pfaffenberger (Eds.), Electricity market reform: An international perspective (pp. 49-74). Amsterdam: Elsevier.

Knittel, C. R. (2006). The adoption of state electricity regulation: The role of interest groups. Journal of Industrial Economics, 54, 201-222.

Kole, S. R., \& Lehn, K. M. (1997). Deregulation, the evolution of corporate governance structure and survival. American Economic Review, Papers and Proceedings, 87, 421-425.

Kole, S. R., \& Lehn, K. M. (1999). Deregulation and the adaptation of governance structure: the case of the U.S. Airline Industry. Journal of Financial Economics, 52, 79-117.

Laffont, J.-J. (1994). The new economics of regulation ten years after. Econometrica, 62, 507-537. 
Leibenstein, H. (1979). A branch of economics is missing: Micro-micro theory. Journal of Economic Literature, 17, 477-502.

Léon, O. G. (1997). On the death of SMART and the birth of GRAPA. Organizational Behavior and Human Decision Processes, 71, 249-262.

Lewis, T. E., \& Meade, R. B. (2007). Alternating currents or counter-revolution? Contemporary electricity reform in New Zealand. Wellington: Victoria University Press.

Littlechild, S. (1983). Regulation of British telecommunications profitability. London: Department of Industry, HMSO.

London, M. (2003). Antecedents and consequences of self-verification: Implications for individual and group development. Human Resource Development Review, 2, 273-293.

Love, I. (2010). Corporate governance and performance around the world: What we know and what we don't. World Bank Research Observer, 25, 1-29.

Lyon, T., \& Hackett, S. (1993). Bottlenecks and governance structures: Open access and long term contracting in natural gas. Journal of Law, Economics, and Organization, 9, 380-398.

Majumdar, S. K. (1997). Incentive regulation and productive efficiency in the US. Telecommunications Industry. Journal of Business, 70, 547-576.

Maloney, M., McCormick, R., \& Tollison, R. D. (1984). Economic regulation, competitive governments, and specialized resources. Journal of Law and Economics, 27, 329-338.

Marris, R. (1963). A model of the managerial enterprise. Quarterly Journal of Economics, 77, 185-209.

McFadden, D. (2009). The human side of mechanism design: A tribute to Leo Hurwicz and Jean-Jacque Laffont. Review of Economic Design, 13, 77-100.

Meyer, J. W., \& Rowan, B. (1991). Institutionalized organizations: Formal structure as myth and ceremony. In W. W. PowelI \& P. J. DiMaggio (Eds.), The new institutionalism in organizational analysis (pp. 41-62). Chicago: University of Chicago Press.

Mikkelsen, A., Nybo, G., \& Gronhaug, K. (2002). Exploring the impact of deregulation on HRM: The case of the Norwegian energy sector. International Journal of Human Resource Management, 13, 942-957.

Mitbestimmung. (2006). Haben die Verbraucher Milliarden zu viel gezahlt? Magazin Mitbestimmung, 07, $10-15$.

Moe, T. M. (1984). The new economics of organization. American Journal of Political Science, 28, 739-777.

Monteverde, K., \& Teece, D. J. (1982). Supplier switching costs and vertical integration in the automobile industry. Bell Journal of Economics and Management Science, 13, 206-213.

Mueller, D. C. (2004). Public choice III. Cambridge, Mass.: Cambridge University Press.

Mueller, F., \& Carter, C. (2007). 'We are all managers now': Managerialism and professional engineering in UK electricity utilities. Accounting, Organization and Society, 32, 181-195.

Narduzzo, A., \& Warglien, M. (2008). Conducting experimental research on organizational routines. In M. C. Becker (Ed.), Handbook of organizational routines (pp. 301-324). Cheltenham: Edward Elgar.

Nee, V. (2005). The new institutionalism in economics and sociology. In N. Smelser \& R. Swedberg (Eds.), The handbook of economic sociology (2nd ed., pp. 49-74). Princeton, NJ: Princeton University Press and Russell Sage Foundation.

Nelson, R., \& Winter, S. (1982). An evolutionary theory of economic change. Cambridge, Mass: Harvard University Press.

Niskanen, W. A. (1971). Bureaucracy and representative Government. Chicago: Aldine.

North, D. C. (1990). Institutions, institutional change and economic performance. Cambridge, Mass: Cambridge University Press.

North, D. C. (1994). Economic performance through time. American Economic Review, 85, 359-368.

OFGEM. (2008). Electricity distribution price control revenue reporting: regulatory instructions and guidance-Version 4, London.

OFGEM. (2010). Consultation on strategy for the next transmission price control: RIIO-T1. London: Overview paper.

Olson, M. (1965). The logic of collective action. Cambridge, Mass.: Harvard University Press.

Peltzman, S. (1976). Toward a more general theory of regulation. Journal of Law and Economics, 19, 211-240.

Pfeifenberger, J. P., \& Tye, W. B. (1995). Handle with care. A primer on incentive regulation. Energy Policy, 23, 769-779. 
Pollitt, M. (2008). The arguments for and against ownership unbundling of energy transmission networks. Energy Policy, 36, 704-713.

Posner, R. A. (1993). The new institutional economics meets law and economics. Journal of Institutional and Theoretical Economics, 149, 73-87.

Powell, W. W., \& DiMaggio, P. J. (1991). Introduction. In W. W. Powell \& P. J. DiMaggio (Eds.), The new institutionalism in organizational analysis (pp. 1-38). Chicago: University of Chicago Press.

Richter, R. (2005). The new institutional economics-Its start, its meaning, its prospects. European Business Organization Law Review, 6, 161-200.

Ritz, A., \& Sager, F. (2010). Outcome-based public management and the balance of powers in the context of direct democracy. Public Administration, 88, 120-135.

Rossi, J. (2008). Public choice, energy regulation and deregulation. Public Law Research Paper: Florida State University College of Law. No. 338.

Russo, M. (1992). Bureaucracy, economic regulation, and the incentive limits of the firm. Strategic Management Journal, 13, 103-118.

Santos, F. M., \& Eisenhardt, K. M. (2005). Organizational boundaries and theories of organization. Organization Science, 16, 491-508.

Schotter, A. (1996). You're not making sense, you're just being logical. In S. G. Medema \& W. J. Samuels (Eds.), Foundations of research in economics: How do economists do economics? (pp. 195-201). Aldershot: Edward Elgar.

Scott, W. R. (2001). Institutions and organizations (2nd ed.). Thousand Oaks: Sage.

Shleifer, A. (1985). A theory of yardstick competition. RAND Journal of Economics, 16, 319-327.

Silva, C., Wollenberg, B. F., \& Zheng, C. Z. (2001). Application of mechanism design to electric power markets. IEEE Transactions on Power Systems, 16, 1-8.

Simon, H. A. (1991). Organizations and markets. Journal of Economic Perspectives, 5, $25-44$.

Spence, D. B. (2008). Can law manage competitive energy markets? Cornell Law Review, 93, 765-817.

Steiner, F. (2001). Regulation, industry structure, and performance in the electricity supply industry. OECD Economic Studies, 32, 143-182.

Stern, J. (1997). What makes an independent regulator independent? Business Strategy Review, 8, 67-74.

Stieglitz, N., \& Heine, K. (2007). Innovations and the role of complementarities in a strategic theory of the firm. Strategic Management Journal, 28, 1-15.

Stigler, G. J. (1971). The theory of economic regulation. Bell Journal of Economics and Management Science, 3, 3-18.

Stinchcombe, A. L. (1965). Social structures and organizations. In J. G. March (Ed.), Handbook of organizations (pp. 142-193). Chicago: Rand McNally.

Tolbert, P., \& Zucker, L. G. (1996). Institutional theory. In S. R. Clegg, C. Hardy, \& W. R. Nord (Eds.), The handbook of organization studies (pp. 175-190). London: Sage.

Tversky, A., \& Kahneman, D. (1974). Judgment under uncertainty: Heuristics and biases. Science, 185, 1124-1131.

Vanberg, V. J. (1992). Organizations as constitutional systems. Constitutional Political Economy, 3, 223-253.

Verma, K., Mitnick, B. M., \& Marcus, A. A. (1999). Making incentive systems work: Incentive regulation in the nuclear power industry. Journal of Public Administration Research and Theory, 9, 395-436.

Viscusi, W. K., Harrington, J. E., \& Vernon, J. M. (2005). Economics of regulation and antitrust (4th ed.). Cambridge, Mass: MIT Press.

Vogelsang, I. (2002). Incentive regulation and competition in public utility markets: A 20-year perspective. Journal of Regulatory Economics, 22, 5-27.

Weick, K. E., Sutcliffe, K. M., \& Obstfeld, D. (2005). Sensemaking and organizing. Organization Science, 16, 409-421.

Williamson, O. E. (1963). A model of rational managerial behavior. In R. M. Cyert \& J. G. March (Eds.), A behavioral theory of the firm (pp. 237-252). Englewood Cliffs, N.J.: Prentice-Hall.

Williamson, O. E. (1985). The economic institutions of capitalism. New York: The Free Press.

Williamson, O. E. (1998). Transaction cost economics: How it works; where it is headed. De Economist, 146, 23-58.

Zey, M. (1998). Rational choice theory and organizational theory: A critique (2nd ed.). Newbury Park: Sage. 


\section{Author Biography}

Klaus Heine is professor of Law and Economics at the Rotterdam Institute of Law and Economics, Erasmus School of Law, Erasmus University Rotterdam. He is also a member of the research group "Behavioral Approaches to Contract and Tort" at the Erasmus School of Law. His main fields of interest are European corporate law, European economic policy (esp. public utilities regulation and state aid control) as well as organizational science and strategic management. He has contributed to numerous academic journals in the fields of law and economics, economic policy and management. 